\title{
UMA PROPOSTA INVESTIGATIVA PARA O ENSINO DE CORES
}

\author{
Thiago Balacó Borrajo ${ }^{1 *}$ Afrênio de Araújo COElHo ${ }^{2 \dagger}$ \\ ${ }^{1}$ Instituto Federal de Educação, Ciência e Tecnologia do Rio Grande do Norte \\ IFRN - Campus Pau dos Ferros - BR 405, KM 154, S/N \\ Chico Cajá, CEP 59900-000 - Pau dos Ferros/RN, Brasil \\ ${ }^{2}$ Departamento de Física - Universidade Federal do Ceará - UFC \\ Campus do Pici - Bloco 922 - Pici, CEP 60440-900 - Fortaleza, Brasil
}

\begin{abstract}
Resumo
Diante de uma realidade de frustração, insatisfação e desinteresse no processo de ensino/aprendizagem de ciências na educação básica, trazemos uma proposta metodológica para o ensino de óptica geométrica, especificamente para o entendimento físico de nossa percepção das cores, baseada em uma atividade investigativa que exige reflexão e raciocínio. Nela, os estudantes são divididos em grupos e precisam debater ideias, construir hipóteses e encontrar meios para comprová-las através de um experimento. Ao final da aula, as conclusões dos grupos são confrontadas com o conhecimento formal, possibilitando a análise de discordâncias e concordâncias com a teoria já estabelecida.
\end{abstract}

Palavras-chave: Ensino, Investigação, Cores.

\footnotetext{
*E-mail: thiago.borrajo@ifrn.edu.br.

†E-mail: afranio@fisica.ufc.br.
} 


\begin{abstract}
In the face of a scene of dissatisfaction and indifference in the process of teaching/learning of science in basic education, we present a proposal for teaching some fundamentals topics of geometrical optics, specifically for the physical understanding of our perception of colors, based on investigative activities that require reflection and reasoning. In it, the students are divided into groups and they need to discuss about ideas, make hypotheses and find ways for prove them. At the end of each class, the group conclusions are confronted with formal knowledge. Making it possible to analyze discrepancies and concordances with the know theory.
\end{abstract}

Keywords: Teaching, Invesigation, Colors.

\title{
1 Introdução
}

Há, entre os professores de ciências dos últimos anos do ensino fundamental e do ensino médio, um forte sentimento de frustração e insatisfação ao se constatar o limitado sucesso da ação docente. Além do crescente desinteresse pelos temas abordados em sala, os alunos aparentam aprender cada vez menos [1]. Por fim, muitos estudantes não conseguem desenvolver as habilidades necessárias para aprender os conteúdos de ciências. Em certas situações, conseguem até realizar os procedimentos exigidos, porém, sem a real compreensão acerca do que estão fazendo. Esses momentos se tornam evidentes na resolução de problemas, nas quais os estudantes costumam adotar procedimentos repetitivos no lugar de enfrentá-los como momentos de reflexão e tomada de decisões [2].

Boa parte da prática escolar, no que diz respeito ao ensino de física, está centrada na solução de problemas. Estes, por sua vez, costumam ser de natureza quantitativa e excessivamente delimitadas, de pouco ou nenhum significado científico. Em uma abordagem sobre leis de Newton, por exemplo, é mais comum encontrar uma questão que solicite do aluno o módulo de uma força resultante que é aplicada sobre um corpo com massa e aceleração conhecidas do que outra que exija dele a compreensão das consequências das leis de Newton no cotidiano como, por exemplo: Por que um veículo menor (moto ou carro de passeio) costuma ter um prejuízo maior quando se choca com um caminhão?

Além disso, mesmo que a escola disponha de aulas de laboratório, estas costumam se resumir a meras demonstrações. Os estudantes têm pouca ou nenhuma liberdade, dada a rigidez que frequentemente temos nos roteiros de uma prática tradicional.

Esses dois pontos, em especial, contribuem muito para o esvaziamento de significado na aprendizagem de ciências, o que resulta em falta de motivação para o aluno.

Com o propósito de oferecer um caminho que conduza o aluno para uma aprendizagem efetiva de ciências, uma real educação científica, o presente trabalho se propõe a apresentar uma metodologia para o ensino de "luz e cores" que tenha como essência o ensino por investigação. Essa metodologia foi aplicada em uma turma de $2^{\circ}$ ano do curso técnico em informática, na forma integrada, do Instituto Federal de Educação, Ciência e Tecnologia do Rio Grande do Norte (IFRN), campus Pau dos Ferros. 


\section{Referencial Teórico}

O grande desenvolvimento científico e tecnológico, especialmente ocorrido nas últimas décadas, transformou o conhecimento nessas áreas em elemento vital para qualquer um que esteja inserido na sociedade. A tecnologia nos rodeia a todo momento, até mesmo como intermediária em nossas comunicações. Viver alheio à essa realidade pode levar o indivíduo ao isolamento e exclusão. É por isso que a educação científica tem se configurado em exigência urgente. Para muitos especialistas, trata-se de um elemento essencial para o desenvolvimento tanto das pessoas quanto dos povos, inclusive a curto prazo [3]. Em Granger[4] temos a afirmação de que, por ser uma criação extraordinária do homem, a ciência pode lhe conferir poder e satisfação intelectual.

Por sua vez, Chassot[5] entende, como a maior responsabilidade no ensino de ciências, a transformação dos estudantes em seres mais críticos. É justamente a partir desse ponto, por meio dessa forma de se fazer a educação, que eles passarão a ser agentes de transformação na sociedade.

"Para que um país esteja em condições de satisfazer as necessidades fundamentadas da sua população, o ensino das ciências e a tecnologia é um imperativo estratégico. Como parte dessa educação científica e tecnológica, os estudantes deveriam aprender a resolver problemas concretos e a satisfazer as necessidades da sociedade, utilizando as suas competências e conhecimentos científicos e tecnológicos. (...) Hoje, mais do que nunca, é necessário fomentar e difundir a alfabetização científica em todas as culturas e em todos os setores da sociedade, (...) a fim de melhorar a participação dos cidadãos na tomada de decisões relativas à aplicação dos novos conhecimentos" [6]

Segundo a UNESCO [6], três grandes metas são fundamentais para a democratização da ciência:

a. Aumentar o número de pessoas diretamente beneficiadas pelos avanços científicos e tecnológicos. Além disso, é necessário priorizar a investigação científica nas regiões mais carentes.

b. Expandir o acesso à ciência: é necessário entendê-la como sendo um elemento central da cultura.

c. O controle social da ciência e da tecnologia e sua orientação. Essa condução deve socorrer de forma clara a partir de decisões morais e políticas da coletividade.

O conhecimento científico se apresenta como instrumento de crescimento e satisfação tanto pessoal quanto social. Trata-se do caminho para o exercício pleno da cidadania, por isso é tão importante que os docentes atuem nessa educação científica [5]. Para que alcancemos esse grau de desenvolvimento, nossa práxis não pode se resumir ao ensino de algoritmos. Não é aceitável que nos contentemos com um ensino de ciências aplicado à situações fora de contexto. Muito além da mera aplicação de fórmulas e cálculos sem significado, é necessário desenvolver metodologias de ensino que conduzam o estudante à resolução de problemas relacionados ao seu cotidiano.

Santos e Schnetzler [7] afirmam que, para uma tomada de decisão, o cidadão necessita tanto de informação quanto de capacidade crítica para análise. Desse modo, é possível avaliar os caminhos possíveis e encontrar uma melhor relação entre custo e benefício. Esses problemas, que se apresentam no 
cotidiano, geralmente não são bem definidos e possuem uma infinidade de alternativas. Já na sala de aula, a realidade é bem distinta. Os problemas, além de definidos com clareza desde o início, já possuem uma solução esperada fazendo com que a avaliação se resuma no que está certo ou errado. Nota-se, aqui, uma grande diferença entre o tratamento de problemas acadêmicos e o tratamento de problemas reais.

É preciso desenvolver competências e habilidades para que os alunos alcancem autonomia a partir do conhecimento científico e tecnológico. Sobre a autonomia, Fourez [8] define que o indivíduo a alcança no momento em que é capaz de tomar decisões razoáveis sem, no entanto, depender de fórmulas prontas, algoritmos ou a orientação direta de especialistas. Essa condição é indispensável para que se obtenha independência no pensar. Os Parâmetros Curriculares Nacionais (PCNs) entendem a autonomia como:

“condição indispensável para os juízos de valor e as escolhas inevitáveis à realização de um projeto próprio de vida, requer uma avaliação permanente, e mais realista possível, das capacidades próprias e dos recursos que o meio oferece (...) porque visa a formar pessoas solidárias e responsáveis por serem autônomas. " [9]

A orientação do ensino para uma "alfabetização científica" não pode ser vista como um empobrecimento dos conteúdos para torná-los mais acessíveis ao público em geral, mas como uma reorganização que busca alterar a imagem distorcida que a ciência possui como sendo algo distante, absoluto e intocável para a maioria. Essa nova formação é importante até mesmo para aqueles que se tornarão especialistas em alguma das áreas da ciência. Esse caminho busca desenvolver o raciocínio crítico, fundamental na tomada de decisões tanto para profissionais quanto para leigos em ciências.

Por isso, se faz tão necessária a aproximação do trabalho de ensino com o trabalho de investigação científica em sala de aula. Integrando aspectos procedimentais, conceituais e axiológicos.

\section{Ensino por Investigação}

Quando falamos em ensino por investigação, estamos tratando de uma modalidade de ensino que desafia o estudante a solucionar problemas. Para tanto, ele deverá utilizar todas as habilidades que possuir à disposição para encontrar uma resposta e, se possível, comprová-la. Esse tipo de atividade, que aproxima o aluno do trabalho científico, proporciona não só uma melhor aprendizagem de ciências, como também um maior desenvolvimento dos conhecimentos conceituais [10]. Essas investigações podem ocorrer tanto por meio de uma prática laboratorial quanto por problemas de lápis e papel. Todo o trabalho deve girar em torno da solução de um problema. Por isso, é importante definirmos, neste ponto, nosso conceito de "problema".

No ensino de física tradicional, "problemas" se resumem aos exercícios dos livros didáticos. Eles costumam ser direcionados para a aplicação das equações a fim de que se obtenham resultados precisos em um processo demasiadamente repetitivo. Gil e Torregrosa [11] consideram que esse tipo de abordagem tende ao operativismo e não à uma investigação na qual se aplique a metodologia científica. $\mathrm{O}$ que vemos nos livros também se reflete na prática docente, especialmente em disciplinas como física e matemática. Tanto na rede pública quanto na rede privada de ensino, uma parte considerável da carga horária de aulas é, frequentemente, direcionada à solução de exercícios dessa natureza. Apesar da larga utilização 
desse método, há uma série de pesquisadores que alertam para o fracasso dessa abordagem, haja vista o desempenho baixo dos estudantes [12-14].

Isso se justifica porque, aparentemente, os estudantes não aprendem sobre como resolver problemas, mas memorizam soluções de acordo com o que lhes é apresentado em sala. Esse automatismo não habilita os alunos para a resolução de casos fora dos modelos já vistos, o que torna a aprendizagem não apenas pouco efetiva como também de pouco significado.

Por isso, definiremos problema como sendo uma situação, quantitativa ou qualitativa, que, quando se busca resolvê-la, não se é conduzido à solução de forma automática ou imediata. A reflexão e a tomada de decisões são necessárias e culminará em uma sequência de passos ou etapas a serem seguidas [13]. Vale ressaltar que esses passos ou etapas são determinadas pelos próprios estudantes, não se trata de um caminho conhecido ou previamente estabelecido pelo professor.

Neste ponto, deparamo-nos com uma limitação da definição. Peduzzi [13], destaca que a diferenciação entre problema e exercício é bastante sutil e depende tanto da experiência do indivíduo como da própria tarefa a ser realizada. Ou seja: para uma pessoa, a situação pode representar um autêntico problema mas, para outra, pode se resumir a um simples exercício já trabalhado em outro momento.

Além disso, no ensino tradicional, costuma-se fazer uma nítida separação entre a teoria, as aulas práticas (quando ocorrem) e a resolução de problemas. Essa fragmentação termina por oferecer ao aluno uma visão distorcida do que é a ciência e, principalmente, de como ela é feita e se desenvolve. No cotidiano de um pesquisador não há esse tipo de separação. Na verdade, sequer é possível distinguir uma atividade da outra, tamanho é o grau de integração e interdependência entre elas. É exatamente essa realidade que devemos buscar em uma metodologia para o ensino de ciências.

Por isso, Carvalho et al. [15] destacam a necessidade de atividades variadas, sempre acompanhadas de situações-problema, que tragam o questionamento e promovam o diálogo. Moreira [16] afirma que os momentos de resolução de problemas que conduzam a uma investigação precisam estar centrados na ação do aluno. Para tanto, os estudantes devem ser conduzidos para um trabalho prático. Segundo Blosser [17], um trabalho investigativo deve provocar uma mudança de atitude tanto no professor quanto no aluno.

Azevedo [18] define que, para considerarmos uma atividade como sendo de investigação, não bastam apenas os trabalhos de manipulação e observação por parte do estudante: é necessário que contenha características de um trabalho científico. Além dos trabalhos citados, é fundamental que o aluno reflita, discuta, explique e relate ao longo da atividade. Isso dará à prática as características de uma investigação científica.

É justamente por isso que o ensino por investigação gira sempre em torno de um problema: É ele que fundamentará a pesquisa dos estudantes trazendo significado e motivação. Lewin e Lomáscolo [19] afirmam que esse processo de buscar a solução de um problema a partir da formulação de uma hipótese e seguindo para a experiência e análise de resultados é capaz de facilitar muito a motivação e fazer com que o aluno adquira atitudes como: curiosidade, desejo de experimentar, duvidar de certas afirmações, confrontar resultados e obtenção de mudanças (conceituais, metodológicas e atitudinais).

Um dos aspectos mais significativos dessa metodologia é a mudança de atitude que ela gera tanto no estudante quanto na prática docente. $\mathrm{O}$ estudante precisa abandonar a postura passiva de um mero observador de aulas expositivas pois deve participar do trabalho investigativo desenvolvendo habilidades como argumentação, interpretação e análise. O professor, além de lançar o problema inicial, deve 
acompanhar as discussões dos grupos, questionar e auxiliar os alunos para que mantenham a coerência em suas ideias, a fim de não perderem o foco.

\section{Descrição do Método}

Para a aplicação da proposta investigativa, inicialmente, deve-se organizar a sala em grupos de, no máximo, seis integrantes cada. Por uma questão de praticidade, o ideal é orientar os alunos para que se unam aos colegas mais próximos. Além de reduzir o tempo com os deslocamentos de estudantes para as equipes, é provável que o grau de afinidade entre os membros do grupo seja maior por já terem o costume de estarem próximos nas aulas convencionais. Essa característica é fundamental para o andamento das discussões pois os discentes não ficam tão temerosos em expor suas ideias. Há que se ter atenção para o caso de alunos que, quando estão juntos, se dispersam com brincadeiras e conversas paralelas. Para não comprometer a atividade, devem ser separados. Outro ponto importante diz respeito à distribuição dos grupos na sala. Deve-se deixar o maior espaçamento possível entre eles pois a investigação requer debate contínuo.

Feita a disposição das equipes, um membro deve ser escolhido para fazer o registro da investigação. Deve-se orientar para que esse aluno seja o mais detalhista possível, tomando nota de todas as ideias lançadas na discussão bem como dos procedimentos adotados para se chegar à resposta e conclusões. Uma folha de papel ofício A4 deverá ser entregue para esse relatório que deverá contar, também, com os nomes dos componentes.

O próximo passo é a apresentação de um problema através de um questionamento ou previsão de um experimento em sala. Fundamentalmente, essa pergunta/previsão precisa gerar o debate e despertar a curiosidade. Para tanto, não deve ser muito específica justamente para promover a multiplicidade de ideias e conclusões. Antes do recebimento de qualquer material além da folha A4 para registros, os grupos precisam formular uma ou mais hipóteses a respeito do problema.

Depois que as equipes chegam às respostas iniciais. Deve-se entregar o material para investigação e permitir que as equipes elaborem um experimento, com a finalidade de comprovar suas hipóteses, e discutam os resultados obtidos. Na entrega de material para investigação, a principal característica dele deve ser a de não exigir um algoritmo: os grupos precisam desenvolver uma forma de comprovar ou refutar suas hipóteses elaborando seu próprio plano de trabalho. No caso de um experimento demonstrativo realizado pelo professor, os grupos precisam identificar evidências que comprovem ou refutem suas hipóteses.

Enquanto as equipes discutem e desenvolvem seus procedimentos investigativos, é de suma importância que o professor circule pela sala, de modo a acompanhar as atividades e orientar os grupos com dificuldades. Essa orientação não consiste em fornecer respostas tampouco em conduzir a prática dos estudantes. $\mathrm{O}$ ideal é que, por meio de perguntas, o docente leve os alunos a refletir e encontrar caminhos.

Feitos os registros, um membro de cada grupo deve ser escolhido, de preferência aquele que fez as anotações, para expor à sala um resumo do que foi desenvolvido pela equipe destacando as principais conclusões. O professor deve estar atento à fala dos alunos para perceber a ideias semelhantes e diferentes entre os grupos. 
A partir dessas ideias, o docente faz uma breve abordagem expositiva do conteúdo, apontando convergências e divergências entre as conclusões da turma. Dessa forma, o professor estabelece um confronto entre o conhecimento formal e os resultados obtidos da prática.

Podemos resumir esse método investigativo em sete passos fundamentais:

a. Organizar a sala em grupos;

b. Lançar uma questão para os alunos;

c. Promover um debate nos grupos (formulação de hipóteses)

d. Entregar material para que os alunos organizem experimentos;

e. Solicitar conclusões dos alunos;

f. Debater, com a sala toda, os resultados obtidos;

g. Confrontar esses resultados com a teoria

É importante destacar que os procedimentos aqui descritos não têm o propósito de estipular uma regra rígida mas apenas apresentar passos que sirvam de referência para que o professor estruture sua própria metodologia. Até porque, em sala de aula, encontramos uma infinidade de realidades diferentes até dentro de uma mesma escola. Não há fórmula que se aplique em todos os ambientes. Por isso, o docente, com sua experiência e conhecimento da turma, deve elaborar o plano de investigação adequado para a sua realidade.

Entretanto, alguns pontos são essenciais para o sucesso de uma abordagem investigativa. O primeiro ponto importante é a organização da sala em grupos para debate e investigação. O segundo é a pergunta que norteará a discussão. Se o professor considerar conveniente, pode elaborar mais de uma pergunta. $\mathrm{O}$ único cuidado aqui é o de adequar os questionamentos ao período da aula a fim de que os alunos tenham tempo hábil para realizar a investigação. O terceiro e último ponto é o compartilhamento de ideias entre alunos e professor.

\section{Desenvolvimento da Metodologia e Resultados}

A aula sobre "luz e cores" foi estruturada com dois objetivos: identificar os fatores que interferem na percepção de cores de um objeto e compreender os processos de reflexão seletiva e refração seletiva da luz.

Inicialmente, os 37 alunos presentes neste dia foram divididos em sete equipes. Duas delas com 6 membros e as demais com 5 membros. O critério para divisão das equipes foi o de proximidade espacial. Ao circular pela sala, determinei quais alunos iriam compor cada uma das equipes. Isso facilitou tanto a montagem dos grupos quanto a disposição deles pela sala. Era importante que houvesse um espaço mínimo entre eles, para que as discussões de um grupo não interferissem tanto em outro, o que se configura em uma tarefa muito difícil para ser realizada em uma sala de aula convencional.

Solicitei aos alunos que escolhessem uma pessoa em cada grupo para registrar as discussões que seriam feitas por eles. Neste dia, orientei que utilizassem uma folha de caderno para esses registros e que o 
entregassem ao fim da aula. Percebi que seria interessante padronizar o material desses relatos entregando uma folha de papel A4, procedimento que passei a adotar nas aulas posteriores. Também fiz a inserção da folha de registros na lista de materiais de todos os roteiros do produto educacional.

Orientei esses estudantes para que se esforçassem em registrar, com todos os detalhes possíveis, o debate de suas respectivas equipes destacando que esses detalhes eram tão importantes quanto uma resposta correta para a questão a ser proposta.

Após essa organização inicial das equipes, lancei para os alunos o seguinte questionamento: O que acontece com a cor de um objeto quando o cobrimos com papel celofane colorido?

Expliquei que, em aproximadamente dez minutos, eles deveriam buscar hipóteses para responder a questão e que, posteriormente, receberiam um material que os auxiliaria a comprovar ou refutar suas ideias.

De início, as equipes chegaram às seguintes conclusões:

(Grupo 1):“A partir da luz que atravessa o papel celofane, a luz chega aos nossos olhos com cor e intensidades diferentes."

(Grupo 4):“O objeto fica da mesma cor do papel."

(Grupo 5):"O papel definirá a cor do objeto quando visto pelos olhos."

(Grupo 6):"O objeto vai ficar, parcialmente, com a cor do papel."

Três grupos acreditavam que haveria uma mistura das cores do papel celofane e do objeto:

(Grupo 2):"Fica uma mistura de cor do papel celofane e do objeto (...) Se o objeto for da mesma cor do papel celofane, não há tanta diferença de observação de cor." (Grupo 5):“A luz refletida se misturará com as do objeto (...). Se o objeto emitisse luz branca, esse objeto refletiria provavelmente a cor do objeto."

(Grupo 7):"Quando há a sobreposição de um papel celofane em um objeto, acontece a junção das cores entre os dois. Porém, quando o objeto for mais claro branco por exemplo - a cor predominante será a do papel celofane."

Após essa formulação de hipóteses, cada grupo recebeu três folhas de papel celofane nas cores verde, vermelha e azul. Também foi entregue um cartão com três círculos coloridos, cada um com uma das cores de papel celofane (Figura 1).

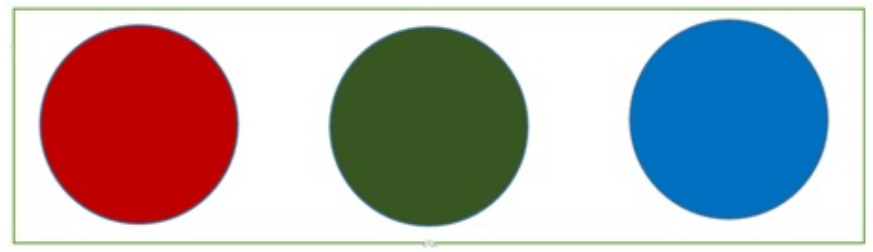

Figura 1: Modelo de cartão com círculos coloridos. Fonte: Autor, 2016.

Os alunos, então, passaram a organizar e registrar a linha de trabalho a ser adotada na atividade com descrição clara da sequência de passos dados (Figura 2). Não há nenhuma orientação específica por parte do professor, os grupos ficam livres até mesmo para utilizar outros materiais que houvesse à disposição 


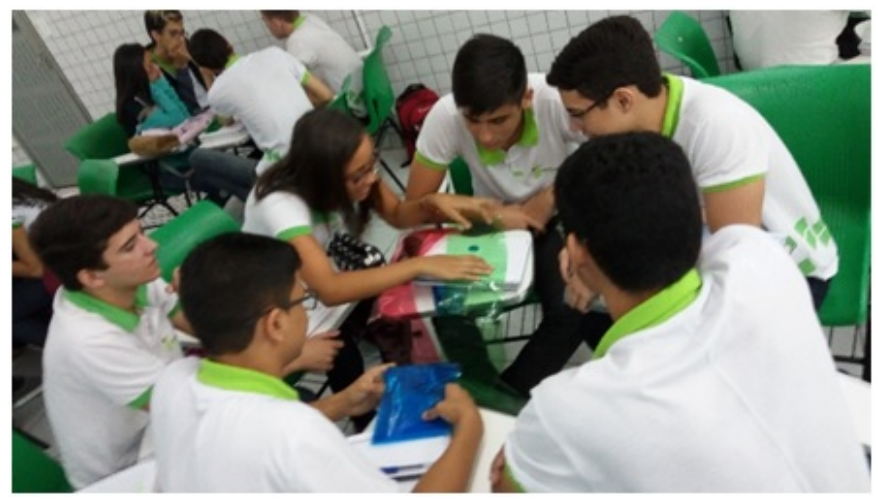

Figura 2: Alunos adotando procedimento experimental. Fonte: Autor, 2016.

Abaixo, a descrição de procedimentos e observações de algumas equipes:

(Grupo 3):“Ao colocar a folha celofane azul sobre o círculo azul, percebemos que não mudou muita coisa. Com o verde a mesma coisa. Ao colocar a folha celofane vermelha dobrada duas vezes. O azul e o verde ficaram mais escuros. Com o azul dobrado duas vezes, percebemos uma mudança no contraste, mas as cores permaneceram as mesmas. Com a folha verde dobrada duas vezes, talvez por ser uma cor mais clara, quase não houve mudanças no cartão."

(Grupo 5):"Colocando uma folha azul em cima das cores, o vermelho ficou preto e as demais cores apenas em tons mais escuros, mas ainda é possível identificá-los. Já com o (papel) verde, o azul ficou preto. Com o (papel) vermelho, azul e verde escurecem."

(Grupo 6): "Primeiro, colocamos os papéis sobre a tirinha de cores e notamos que quanto maior a diferença entre a frequência das cores, ela irá mudar. No caso do papel azul, o vermelho fica preto e o verde ficou mais escuro, já no papel vermelho o azul fica preto e o verde continua ficando mais escuro e no papel verde as três cores ficam mais escuras. No papel celofane vermelho, as cores mais claras ele absorve e as mais escuras ficam pretas, no azul acontece o inverso e no verde todas as cores são absorvidas."

Foi interessante perceber o grau de envolvimento dos estudantes. Enquanto passava por eles, percebi muitos realmente empolgados com o debate. Por isso, circular pelos grupos, ainda que não se tenha interação com eles, é uma das ações mais importantes do docente nesta hora. Á distância, pode-se ter a impressão de que os grupos estão com conversas paralelas à atividade e se dispersando, pois a sala de aula fica bastante ruidosa. Ao longo da atividade, reservei alguns momentos para ouvir das equipes o que estavam pensando no momento e como fizeram o procedimento experimental. Quando notava algum desinteresse ou dúvida, fazia questionamentos a fim de orientar o grupo.

O maior problema que observei foi no procedimento experimental. A maior parte das equipes estava fazendo a análise colocando sobre o cartão com os círculos apenas uma camada de papel celofane. Como a refração seletiva do material possui limitações, é importante verificar o que acontece com as cores também quando dobramos o papel celofane, a fim de obter-se um maior número de camadas. Por isso, 
interrompi momentaneamente a atividade e solicitei a atenção dos alunos. Trouxe mais questionamentos: vocês experimentaram dobrar o papel celofane e observar se há alteração nas cores? Será que o número de camadas (de um celofane de mesma cor) influencia também?

Ao fim da atividade, os grupos fizeram o registro de suas conclusões, como as destacadas abaixo:

(Grupo 1): “Quando a luz atravessou o objeto, essa luz adquire a tonalidade do material que ela refletiu. A luz atua como determinante das cores."

(Grupo 2): “O nível de alteração depende da composição da cor do objeto. Caso o papel verde seja colocado sobre o objeto azul e vermelho, por exemplo, no azul a alteração será menor, devido ao fato desta cor compor sua origem, já na parte vermelha, a alteração é maior, considerando que o vermelho não compõe verde e vice-versa. Caso a superfície seja branca, cor composta pela mistura de todas as cores, ele tenderá a cor (do papel celofane) que está sobre ela."

(Grupo 3):“A cor mais clara no papel celofane, o azul, causou maior efeito na cor mais escura da tabela, o vermelho. E a cor mais escura do papel celofane causou maior efeito nas cores mais claras da tabela, principalmente, na azul. Nos dois casos, as cores que mais sofreram alterações ficaram próximas ao preto. E no terceito caso, colocando o papel verde sobre a tabela, percebemos que causou mais efeito nas cores azul e vermelho."

(Grupo 4):“A cor branca, que está no papel e na cadeira, fica a mesma cor do papel celofane."

(Grupo 5):“A cor do papel (celofane) intensifica a cor igual a dele. Cores parecidas também se intensificam."

(Grupo 6): “Quanto maior a diferença entre a frequência das cores, mais ela irá mudar.

(Grupo 7):“Quando sobrepomos uma cor em outra, há a junção das duas, escurecendo esse resultado. Se uma das cores for clara, branca por exemplo, predominará como resultado a cor mais escura."

Sobre as ideias apresentadas, é importante destacar alguns pontos importantes nas conclusões das equipes. $\mathrm{O}$ grupo 1 destacou que a luz é um fator determinante na percepção das cores. $\mathrm{O}$ grupo 2 chamou a atenção de que a luz branca é composta por todas as cores e, portanto, um objeto branco reflete a cor do papel celofane que estiver sobre ele, a mesma ideia também surge nos comentários das equipes 4 e 7 . Os grupos 3 e 7 registraram o escurecimento de objetos com cor diferente da do papel celofane enquanto o grupo 5 percebeu que, quando o objeto tem a mesma cor do papel celofane, sua cor é "intensificada".

Finalizada a investigação nos grupos, um representante de cada equipe expôs, para a turma, quais foram as hipóteses iniciais, o procedimento adotado, os resultados e as conclusões a que chegaram na atividade.

A partir dessas apresentações, especialmente das conclusões, foi possível fazer um breve momento de aula expositiva abordando o funcionamento da nossa percepção de cores. Além da reflexão e refração seletivas, tratamos também da composição das cores bem como das diferenças entre uma combinação de luzes coloridas e uma mistura de pigmentos coloridos (como a tinta). 


\section{Considerações Finais}

Analisando o desempenho dos alunos, registrados na descrição da aula, e a avaliação qualitativa realizada com os mesmos, percebe-se que o roteiro de aula proposto nesta metodologia atende ao objetivo de transformar o estudante em agente do seu próprio processo de aprendizagem, além de fazer com que ele se sentisse motivado a arriscar respostas aos problemas apresentados e comprová-los.

O ensino por investigação se apresentou, ao longo deste trabalho, como uma ferramenta importantíssima no processo de ensino/aprendizagem. Os problemas conseguiram despertar o interesse dos estudantes e motivá-los na busca por soluções. Os elementos de pesquisa científica, inseridos nas aulas, tornaram as ações em sala bastante produtivas.

No entanto, propor novas metodologias de ensino é sempre uma tarefa difícil, pois sempre traz consigo a necessidade de revisão e crítica do trabalho docente. Trata-se de uma ação de extrema complexidade, especialmente quando já se tem larga experiência na profissão. Arriscar-se em algo novo coloca o profissional em uma área de instabilidade, na qual o fracasso é uma possibilidade real.

Há que se considerar também que os docentes que hoje pesquisam e desenvolvem novos métodos em educação passaram, na maioria dos casos, por um ensino tradicional pautado quase que exclusivamente em aulas expositivas e exercícios descontextualizados.

É relevante destacar que o acerto do aluno, durante uma das práticas propostas neste texto, não é tão significativo quanto os caminhos adotados por ele para se chegar à resposta. Não se trata de reduzir o valor da resposta correta mas sim de promover uma educação científica que gere autonomia nos estudantes.

Os relatórios dos alunos, citados ao longo do texto, nos revelam como eles conseguiram desenvolver uma atitude científica ao longo das investigações, de que modos buscaram comprovar suas hipóteses e o que representaram os resultados obtidos para as ideias iniciais.

A proposta de ensino por investigação, apresentada neste texto, não tem a pretensão de transformar os alunos em cientistas tampouco de fazer com que eles descubram as mesmas leis físicas definidas no passado [18]. É preciso considerar que o conhecimento científico é construído e reformulado ao longo dos anos e com o envolvimento de muitas pessoas. Não é possível reconstruir anos de pesquisa científica em uma atividade em sala de aula nem mesmo resumir uma infinidade de experimentos em uma única prática. O grande foco da metodologia é despertar o interesse do aluno, torná-lo mais receptivo aos novos conhecimentos através da problematização e do debate com os colegas e com o professor.

Cabe chamar a atenção que essa atividade investigativa, por si só, não é capaz de conduzir e formar o aluno. Por isso, é importante atrelar a prática à um momento de aula expositiva que utilize os próprios apontamentos dos estudantes como ponto de partida. Desse modo, podemos comparar as concordâncias e discordâncias das observações com a teoria. Por isso, é vital que o docente esteja atento e acompanhe as conclusões dos grupos.

Com essa metodologia, é possível fazer do estudante um agente no seu próprio processo de aprendizagem, desenvolvendo suas habilidades e capacidades. Além disso, torna-o mais receptivo aos momentos de aula expositiva. 


\section{Referências}

[1] POZO, J.I., GÓMEZ CRESPO, M.A. A Aprendizagem e o Ensino de Ciências: do conhecimento cotidiano ao conhecimento científico. Porto Alegre: Artmed, 2009.

[2] CABAllER, M.J., ONÕRBE, A. Resolución de problemas y Actividades de Laboratorio. Em Carmen, L. del (ed.). Cuadernos de Formación del profesorado de educación secundária: Ciencias de la naturaleza. Barcelona: Horsori, 1997.

[3] GIL-PÉREZ, D., VILCHES, A. ¿Alfabetización científica del conjunto de la ciudadanía? Un debate crucial. Cultura y Educación, 2004.

[4] GRANGER, G. G. A ciência e as ciências. São Paulo. Editora da Unesp, 1994.

[5] CHASSOT, A. Alfabetização científica: questões e desafios para a educação. Ijuí. Editora Unijuí, 2011.

[6] CONFERENCIA MUNDIAL SOBRE LA CIENCIA (1999), La Ciencia para el siglo XXI - Un nuevo compromisso, Budapeste. UNESCO, Paris, 2000.

[7] SANTOS, W. L. P., SCHNETZLER, R. P. Educação em química: compromisso com a cidadania. Ijuí. Editora Unijuí, 2007.

[8] FOUREZ, G. Alfabetización Científica Y Tecnológica. Acerca de las finalidades de la enseñanza de las ciencias. Buenos Aires. Ediciones Colihue, 1997.

[9] BRASIL, Ministério da Educação, Secretaria de Educação Média e Tecnológica. Parâmetros Curriculares Nacionais: ensino médio. Brasília: Ministério da Educação, 2000.

[10] HODSON, D. In Search of a Meaninful Relationship: an exploration of some issues relating to integratin in science and science education. International Journal of Science Education. 14(5), p. 541-566, 1992.

[11] GIL PÉREZ, D., TORREGROSA, J. M. La Resolución de Problemas de Física: Una Didáctica Alternativa. Madrid/ESP: Ministerio de Educación y Ciencia; ed. Vicensvives, 1987.

[12] POZO, Juan Ignácio; CRESPO, Gómez M. A. Aprender y Enseñar Ciencia. Madrid/ESP: Morata, 1998.

[13] PEDUZZI, Luiz O.Q. Sobre a resolução de problemas no ensino da física. In: Caderno Catarinense de Ensino de Física, Florianópolis/BRA, UFSC, v.14 n.3, p.229-253, 1997.

[14] ESCUDERO, C. Resolución de problemas em física: herramienta para reorganizar significados. In: Caderno Catarinense de Ensino de Física, Florianópolis/BRA, UFSC, v.12 n.02, p.95-106, 1995. 
[15] CARVALHO, A.M.P. et al. El papel de las actividades en la construcción del conocimiento en clase. Investigación en la Escuela, (25), p. 60-70, 1995.

[16] MOREIRA, M.A. Uma abordagem cognitivista ao ensino de física. Porto Alegre: Editora da Universidade, 1983.

[17] BLOSSER, P.E. O papel do laboratório no ensino de ciências. Tradução M.A Moreira. Cad. Cat. Ensino de Física,5 (2), pg 74-78, 1988.

[18] AZEVEDO, M.C.P.S. Ensino por investigação: problematizando as atividades em sala de aula. Ensino de ciências: unindo a pesquisa e a prática. Anna Maria Pessoa de Carvalho (Org). São Paulo. Thomson, 2006.

[19] LEWIN, A.M.F. e LOMÁSCOLO, T.M.M. La metodología científica en la construcción de conocimientos. Enseñanza de las ciencias, 20 (2), p. 147-1510, 1998. 